\title{
Environmental Degradation due to Tobacco Cultivation in Northern Bangladesh
}

\author{
Md. Tareq Bin Salam, S. M. Shahriar Zaman, S. M. Tanzim Hossen and Md. Asaduzzaman Nur
}

Soil, Water and Environment Discipline, Khulna University, Khulna 9208, Bangladesh

Manuscript received: 28 December 2020; accepted for publication: 13 April 2021

\begin{abstract}
A field study was conducted in Northern Bangladesh, Rangpur district to observe the impact of tobacco cultivation on the environment as well as to characterize contributing factors motivating tobacco cultivation. Information was collected from the tobacco cultivators by a questionnaire survey that was conducted in four mostly tobacco cultivated upazilas, namely Badargonj, Taragonj, Rangpur Sadar, Gangachara of Rangpur district. Information from non-tobacco cultivators was also collected from Mithapukur Upazila. Survey findings revealed that $62.16 \%$ of respondents believed that soil productivity is decreasing in the tobacco field and $70.27 \%$ of tobacco farmers were using more chemical fertilizer per year than the previous years. More than half $(54.05 \%)$ of respondents reported that tobacco is replacing native food crops. Moreover, $51.30 \%$ of tobacco farmers were facing various health hazards due to tobacco cultivation. The present study also investigated that $97.14 \%$ of farmers got a high benefit along with $89.19 \%$ of respondent's availed organizational support from tobacco marketing companies. The overall satisfaction rate with the price was $80.56 \%$, which was the main contributory factor for tobacco cultivation in the study area. The survey results also identified that farmers from Mithapukur Upazila gave up tobacco cultivation due to health hazards and unnecessarily underestimating the grade of tobacco leaf by the buyer company.
\end{abstract}

Keywords: Farmer, Economic impact, Health impact, Contributory factor, Tobacco cultivation

\section{INTRODUCTION}

Bangladesh is mainly an agricultural country and the national economy is also based on it. Bangladesh has been renowned for growing a large variety of tropical crops particularly rice, wheat, tobacco, jute, pulses, oilseeds, sugarcane, etc. The tobacco industry is prospective and about one percent of our GDP is used in spending on tobacco products (Hassan et al., 2015). Tobacco is now one of the most health threatening items of our earth resources. The hazardous consequences of the tobacco industry are enormous in terms of different environmental factors like deforestation, climate change, impact on biodiversity and ecological imbalance by producing many toxic waste products (WHO, 2017). Globally tobacco is listed as 2 nd major reason for the death of the world and the alarming part is that around 5.4 million people lost their lives in a premature stage (WHO, 2008). Tobacco cultivation has negative environmental impacts such as declination of biodiversity, erosion and degradation of the soil, water

Corresponding author: Md. Tareq Bin Salam

Email: tareqss@ swe.ku.ac.bd

DOI: https://doi.org/10.3329/dujees.v9i2.55086 pollution and contamination, and an effective rising of carbon dioxide in the atmosphere (Lecours et al., 2012). Every year around the world, 4.3 million hectares of the agricultural land is used for tobacco cultivation resulting in global deforestation between $2 \%$ to $4 \%$ and it creates more than 2 million tons of solid waste. It is recorded from 1995 to 2015, tobacco formulation will produce a total of 45 tons of solid, 6 million tons of nicotine waste, and over 4 million tons of chemical waste (Novotny and Zhao, 1999). In large scale tobacco has been brought in the mid-sixties into the fields where food crops were grown, and more extensively after liberation in 1971 by the British American Tobacco Company in Testa silt in Rangpur District area. Rangpur district is in leading position among the tobacco cultivation districts in Bangladesh. According to a DAE report in (2020) Taragonj, Sadar, Gangachara, and Badargonj are the most tobacco producing upazilas (sub-districts) of Rangpur district. Researches show that tobacco farmers are experiencing some health risk in tobacco cultivation areas. It also causes environmental degradation. So, this study was carried out in 5 upazilas of Rangpur district to investigate the influence of tobacco cultivation on environmental degradation along with identifying the main contributing factors for motivating or demotivating tobacco cultivation. 


\section{MATERIALS AND METHODS}

\section{Selection of Study Area}

Among Tobacco cultivation practicing districts, Rangpur district was purposively chosen for the study. The criterion for selecting a site was the availability of tobacco cultivators. Information was collected through personal communication, and own investigation. During the study, a multistage sampling technique was adopted. Among 8 upazilas, 4 upazilas: Badargonj, Taragonj, Rangpur Sadar, and Gangachara were enrolled for data collection from tobacco cultivators, and Mithapukur upazila was selected for collecting information from non-tobacco cultivators (Table 1).

Table 1: GPS Location of the Study Area

\begin{tabular}{ll}
\hline Study Area (Upazila) & Location (GPS) \\
\hline Badargonj & $89^{\circ} 04^{\prime} \mathrm{E}, 25^{\circ} 43^{\prime} \mathrm{N}$ \\
Taragonj & $89^{\circ} 06^{\prime} \mathrm{E}, 25^{\circ} 39^{\prime} \mathrm{N}$ \\
Rangpur Sadar & $89^{\circ} 08^{\prime} \mathrm{E}, 25^{\circ} 49^{\prime} \mathrm{N}$ \\
Gangachara & $89^{\circ} 11^{\prime} \mathrm{E}, 25^{\circ} 49^{\prime} \mathrm{N}$ \\
Mithapukur & $89^{\circ} 18^{\prime} \mathrm{E}, 25^{\circ} 31^{\prime} \mathrm{N}$ \\
\hline
\end{tabular}

\section{Tobacco Cultivation Status of Study Area}

Intensive cultivation of tobacco is found in Rangpur district among the tobacco farming districts in Bangladesh. According to the DAE (2020) cultivation area in different upazilas was reduced compared to 2015-16. Table 2 shows upazila wise cultivation area and production of tobacco of Rangpur district from 2015-16 to 2018-19.

\section{Selection of the Respondents}

From each upazila, 100 respondents were chosen randomly for interview. A total of 400 tobacco cultivators and 100 non-tobacco cultivators were selected purposively from 5 upazilas. A detailed socio-economic survey was conducted to assess educational status, age, sex, land tenure status, present practices, occupation, and income per annum of tobacco cultivation and impacts on the environment. The respondents were characterized according to their sex, age, and socio-economic status that were presented in Table 3.

Table 2: Tobacco Cultivation Status of the Study Area

\begin{tabular}{l|cc|cc|cc|cc}
\hline \multirow{4}{*}{ Upazila } & \multicolumn{2}{|c|}{$2018-19$} & \multicolumn{2}{c|}{$2017-18$} & \multicolumn{2}{c|}{$2016-17$} & \multicolumn{2}{c}{$2015-16$} \\
\cline { 2 - 9 } & $\begin{array}{c}\text { Cultivation } \\
\text { (ha) }\end{array}$ & $\begin{array}{c}\text { Production } \\
\text { (MT) }\end{array}$ & $\begin{array}{c}\text { Cultivation } \\
\text { (ha) }\end{array}$ & $\begin{array}{c}\text { Production } \\
\text { (MT) }\end{array}$ & $\begin{array}{c}\text { Cultivation } \\
\text { (ha) }\end{array}$ & $\begin{array}{c}\text { Production } \\
\text { (MT) }\end{array}$ & $\begin{array}{c}\text { Cultivation } \\
\text { (ha) }\end{array}$ & $\begin{array}{c}\text { Production } \\
\text { (MT) }\end{array}$ \\
\hline Metro & 50 & 85 & 25 & 42 & 8 & 13 & 80 & 128 \\
Sadar & 320 & 508 & 250 & 388 & 100 & 161 & 100 & 146 \\
Kaunia & 3 & 5 & 0 & 0 & 0 & 0 & 0 & 0 \\
Gangachara & 300 & 512 & 565 & 951 & 500 & 893 & 850 & 1680 \\
Mithapukur & 0 & 0 & 0 & 0 & 0 & 0 & 0 & 0 \\
Pirgonj & 0 & 0 & 0 & 0 & 0 & 0 & 0 & 0 \\
Pirgacha & 0 & 0 & 0 & 0 & 0 & 0 & 0 & 0 \\
Badargonj & 17 & 29 & 38 & 62 & 55 & 95 & 65 & 106 \\
Taragonj & 850 & 1563 & 510 & 939 & 502 & 842 & 500 & 819 \\
Total & 1540 & 2702 & 1388 & 2382 & 1165 & 2004 & 1595 & 2879 \\
\hline
\end{tabular}

Source of Data: DAE 2020

Table 3: Respondents' Characterization

\begin{tabular}{ccccccc}
\hline 1 & Sex & \multicolumn{2}{c}{ Male } & \multicolumn{2}{c}{ Female } \\
\hline 2 & Age (Years) & $<25$ & $25-35$ & $35-45$ & $45-55$ & $>55$ \\
\hline \multirow{2}{*}{3} & \multirow{2}{*}{ Educational Qualification } & \multirow{2}{*}{ Illiterate } & \multirow{2}{*}{ Primary } & Secondary & $\begin{array}{c}\text { Higher } \\
\text { Secondary }\end{array}$ & Graduation \\
\hline \multirow{2}{*}{4} & \multirow{2}{*}{ Farm Size } & \multicolumn{2}{c}{ Small } & \multicolumn{2}{c}{ Medium } & Large \\
\cline { 3 - 6 } & \multirow{2}{*}{ Occupational Status } & Farmer & Business & Service & Student \\
\hline
\end{tabular}




\section{Procedure for Collecting Data}

The study was both explorative and descriptive that mixed with qualitative and quantitative data as well as secondary and primary data. The primary data were collected through a structured questionnaire survey, interviews, FGD (focus group discussion), and observations. The secondary data were collected from different sources like the Department of Agricultural Extension (DAE), Rangpur, Bangladesh. The questionnaire survey was conducted based on multistage and purposive sampling which included 50 respondents.

\section{Data Analysis Technique}

Collected quantitative data were analyzed by their frequencies and percentages using statistical software: MS Excel. The Benefit-Cost ratio of tobacco cultivation was calculated by the following formula (Hassan et al., 2015):

$$
\text { Benefit }- \text { Cost Ratio }=\frac{\text { Total Revenue }}{\text { Total Cost }}
$$

Where, Total Revenue is the total outcome of the tobacco cultivation.

\section{RESULTS AND DISCUSSION}

\section{Socioeconomic Status of Respondents}

Respondents' responses were categorized according to their age, sex, occupation, education, and farm size are described here (Table 4).

Table 4 stated that $28 \%$ of the respondents were in the age group $45-55$ where only $4 \%$ of respondents' age was less than 25 years.

Among the respondents $90 \%$ were farmer where only $2 \%$ were student and $2 \%$ service holder who were cultivating tobacco besides their occupation (Table 4).

Research found that farmers with a minimum of education were very much aware of the harmful effects of tobacco cultivation. In this study, $26 \%$ of the respondents were illiterate and $34 \%$ hardly completed their primary education and $28 \%$ passed the secondary level. Eight percent of the respondents completed their graduation and involved with tobacco cultivation. So, it can be stated that the educational status of the farmers is a very relevant factor of tobacco cultivation (Table 4).
Table 4: Socio-economic Status of Respondents

\begin{tabular}{|c|c|c|}
\hline Categories & Frequency & Percent $(\%)$ \\
\hline \multicolumn{3}{|c|}{ Age Distribution of the Respondents } \\
\hline$<25$ years & 2 & 4 \\
\hline $25-35$ years & 9 & 18 \\
\hline $35-45$ years & 13 & 26 \\
\hline $45-55$ years & 14 & 28 \\
\hline$>55$ years & 12 & 24 \\
\hline Total & 50 & 100 \\
\hline \multicolumn{3}{|c|}{ Occupational Status of the Respondents } \\
\hline Farmer & 45 & 90 \\
\hline Business & 3 & 6 \\
\hline Service & 1 & 2 \\
\hline Student & 1 & 2 \\
\hline Total & 50 & 100 \\
\hline \multicolumn{3}{|c|}{ Educational Status of the Respondents } \\
\hline Illiterate & 13 & 26 \\
\hline Primary & 17 & 34 \\
\hline Secondary & 14 & 28 \\
\hline Higher Secondary & 2 & 4 \\
\hline Graduation & 4 & 8 \\
\hline Total & 50 & 100 \\
\hline \multicolumn{3}{|c|}{$\begin{array}{l}\text { Distribution of the Respondents According to Their Farm } \\
\text { Size }\end{array}$} \\
\hline Small (0.01-0.33 acre) & 5 & 10 \\
\hline Medium (0.34-1.0 acre) & 27 & 54 \\
\hline Large $(>1$ acre $)$ & 18 & 36 \\
\hline Total & 50 & 100 \\
\hline
\end{tabular}

In this study, the respondents were classified into small, medium, and large farmers according to their farm size. Table 4 pointed out that $54 \%$ of respondents were medium farmer who had 0.34-1.0 acre of land for cultivation.

\section{Impact Analysis}

\section{Impact on Soil}

According to Table 5, 62.16\% of respondents believed that soil is continuously losing its productivity along with $70.27 \%$ of respondents agreed on using more chemical fertilizer in their soil than ever before (Table 5).

Survey result also depicted that $43.24 \%$ of the respondents believed that soil productivity is decreasing too much and $35.14 \%$ of the respondents said that they are increasing too much use of chemical fertilizer every year (Table 5).

So, it can be indicated that soil productivity is decreasing day by day due to tobacco cultivation and farmers are increasing chemical fertilizer application every year. Moula et al. (2018) in their study on 
Bheramara Upazila in Khustia District found that frequent farming of tobacco in the same land reduced soil fertility in almost all tobacco plots. Geist (1999) reported that tobacco cultivation decreases soil fertility than any other crop as it absorbs more nitrogen, phosphorus, and potassium than other cultivating crops. He also added that two specific method of tobacco cultivation - topping and suckering gain a high level of nicotine and more leaves that also decreases soil fertility. Yanda (2010) found in his study that tobacco cultivation caused a severe level of soil degradation in Tanzania. Similar findings were also found by Hossain et al. (2013).

\section{Impact on Air}

Survey result illustrated that $54.05 \%$ of the respondents gave a negative response on the impact of tobacco cultivation on-air. Whereas $18.92 \%$ reported that the impact of tobacco cultivation on-air was too much (Table 6).
Ali et al. (2015) in their study found a significant effect of tobacco processing on air pollution. They also claimed that $80 \%$ of respondents reported too much impact of tobacco processing on air pollution. Lecours et al. (2012) reported that tobacco cultivation causes air pollution and other environmental degradation.

\section{Impact on Social Environment}

Table 7 demonstrated that $54.05 \%$ of the respondents reported that people are changing their selection of crops, even some cases changing occupations and getting interested in tobacco cultivation. Having tobacco cultivation improves their social status because they believed that tobacco could ensure their money flow thus improve their lifestyle. The most important fact is that $78.38 \%$ of the respondents had a positive opinion about the involvement of their family members in tobacco farming. So, it can be said that tobacco cultivation has its impact on the social environment also.

Table 5: Impact of Tobacco Cultivation on Soil

\begin{tabular}{|c|c|c|c|c|c|}
\hline Sl. No. & & mer's Response & & \multicolumn{2}{|c|}{ Response (\%) } \\
\hline \multirow{4}{*}{1.} & \multirow{2}{*}{\multicolumn{3}{|c|}{ Soil Productivity is Decreasing due to Tobacco Cultivation }} & Yes & No \\
\hline & & & & 62.16 & 37.84 \\
\hline & \multicolumn{5}{|c|}{ Degree of Impact on Soil Productivity } \\
\hline & Too Much- $43.24 \%$ & Much-5.41\% & A Little- $10.81 \%$ & & $2.70 \%$ \\
\hline \multirow{4}{*}{2.} & \multirow{2}{*}{\multicolumn{3}{|c|}{ Farmers Need to Provide more Chemical Fertilizer Each Year for Production }} & Yes & No \\
\hline & & & & 70.27 & 29.73 \\
\hline & \multicolumn{5}{|c|}{ Degree of Using Chemical Fertilizer } \\
\hline & Too Much-35.14\% & Much-27.03\% & A Little- $2.70 \%$ & \multicolumn{2}{|c|}{ ittle-5.41\% } \\
\hline
\end{tabular}

Table 6: Impact of Tobacco Cultivation on Air

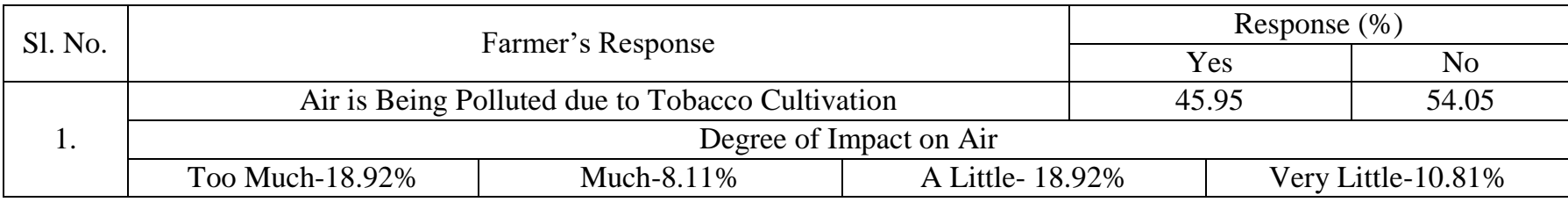

Table 7: Impact of Tobacco Cultivation on Social Environment

\begin{tabular}{|c|l|c|c|}
\hline \multirow{2}{*}{ Sl. No. } & \multicolumn{1}{|c|}{ Farmers' Response } & \multicolumn{2}{|c|}{ Response (\%) } \\
\cline { 3 - 4 } & \multicolumn{1}{|c|}{ Yes } & No \\
\hline 1. & Discrimination is being happened in society due to tobacco cultivation & 37.84 & 62.16 \\
\hline 2. & Addiction is increasing in youth due to tobacco cultivation & 21.62 & 78.38 \\
\hline 3. & $\begin{array}{l}\text { People are changing their selection of crop and occupation by getting interested in } \\
\text { tobacco cultivation }\end{array}$ & 54.05 & 45.95 \\
\hline 4. & Tobacco cultivation impacts on your social status & 54.05 & 45.95 \\
\hline 5. & Tobacco cultivation hampering family peace & 29.73 & 70.27 \\
\hline 6. & Child labor is increasing due to tobacco cultivation & 16.22 & 83.78 \\
\hline 7. & Family members are getting involved in tobacco cultivation & 78.38 & 21.62 \\
\hline 8. & Education of family members is hampered due to tobacco cultivation & 27.03 & 72.97 \\
\hline
\end{tabular}


Tobacco poses health problems with negative impacts on the quality of living of the farmers and reported the involvement of family members in tobacco farming. Rimmer (2004) indicated that since casual agricultural workers are nearly impossible to find, farmers are forced to use their families to help them cultivate and perform other physically demanding tasks in the fields.

\section{Impact on Economic Status of Farmers}

The survey results also explained that almost all the tobacco growers were benefited from tobacco cultivation (97.14\%) and they were getting help from different tobacco companies (89.19\%). Fixed markets were available in the respected area $(97.30 \%)$ where tobacco growers can sell their products and they were also satisfied with the company price $(80.56 \%)$. Among the respondents, $51.43 \%$ were much benefited and $58.33 \%$ were much satisfied with the price (Table $8)$.

Hossain and Rahman (2013) in their study on socioeconomic analysis of tobacco cultivation in Kushtia district of Bangladesh found that $95.4 \%$ of respondents said that tobacco cultivation is more profitable and $61.5 \%$ of respondents said that they are getting loan or financial support from the tobacco company.

\section{IMPACT ON PUBLIC HEALTH}

In the study area, tobacco farming was becoming a threat to public health where $51.35 \%$ of the tobacco growers, were facing different kinds of health hazards where headache and coughing are the major health problems (Table 9).

Similarly, Arcury et al. (2003 a, b) in their study found that up to $89 \%$ of workers can contract the green tobacco sickness (GTS) during cutting, manual harvesting, and manual loading of tobacco processing caused by a nicotine absorption into the skin and the respiratory system. They also reported that symptoms of intoxication include drooling, vomiting, nausea, migraine, diarrhea, respiratory distress, heart rate changes, and increased blood pressure among the tobacco workers, and not only for smoking damage but also the reason is that tobacco is cataloged in the poison of toxic plants for humans. Hu and Lee (2016) reported similar health problems in China, Tanzania and Kenya. According to WHO (2017) tobacco use is a threat to every person, regardless of sex and age and about $80 \%$ of premature deaths related to tobacco occur mainly in several low- and middle-income countries. In the study of Paul et al. (2019), farmers reported that they are experiencing breathing difficulties during fertilizer and pesticide application in the tobacco field.

Table 8: Impact of Tobacco Cultivation on Economic Status of Farmers

\begin{tabular}{|c|c|c|c|}
\hline \multirow{2}{*}{ Sl. No. } & \multirow{2}{*}{ Farmer's Response } & \multicolumn{2}{|c|}{ Response (\%) } \\
\hline & & Yes & No \\
\hline \multirow{3}{*}{1.} & Farmers are Benefitted from Tobacco Cultivation & 97.14 & 2.86 \\
\hline & \multicolumn{3}{|l|}{ Degree of Benefit } \\
\hline & Too Much-22.86\% & \multicolumn{2}{|c|}{ A Little-25.71\% } \\
\hline 2. & Farmers are getting support from the tobacco company & 89.19 & 10.81 \\
\hline 3. & Farmers are selling their products in the fixed market & 97.30 & 2.70 \\
\hline \multirow{3}{*}{4.} & Farmers are satisfied with the price given by the tobacco company & 80.56 & 19.44 \\
\hline & \multicolumn{3}{|l|}{ Degree of Satisfaction } \\
\hline & Too Much-11.11\% & \multicolumn{2}{|c|}{ A Little-11.11\% } \\
\hline
\end{tabular}

Table 9: Impact of Tobacco Cultivation on Public Health

\begin{tabular}{|c|c|c|c|c|c|}
\hline \multirow{2}{*}{ Sl. No. } & \multirow{2}{*}{\multicolumn{3}{|c|}{ Farmer's Response }} & \multicolumn{2}{|c|}{ Response (\%) } \\
\hline & & & & Yes & No \\
\hline & \multicolumn{3}{|c|}{ Farmers are Suffering from Health Hazard due to Tobacco Cultivation } & 51.35 & 48.65 \\
\hline & \multirow{9}{*}{$\begin{array}{l}\text { Health Hazards that } \\
\text { Farmers are Suffering } \\
\text { from }\end{array}$} & Health hazards & Response (\%) & \multicolumn{2}{|c|}{ Ranking } \\
\hline & & Headache & 19.10 & \multicolumn{2}{|c|}{1} \\
\hline & & Coughing & 17.98 & \multicolumn{2}{|c|}{2} \\
\hline & & Vertigo & 16.85 & \multicolumn{2}{|c|}{3} \\
\hline & & Vomiting & 15.73 & \multicolumn{2}{|c|}{4} \\
\hline & & Asthma & 14.61 & \multicolumn{2}{|c|}{5} \\
\hline & & Spot in Skin & 6.74 & \multicolumn{2}{|c|}{6} \\
\hline & & Eye irritation & 6.74 & \multicolumn{2}{|c|}{6} \\
\hline & & Gum disease & 1.12 & \multicolumn{2}{|c|}{7} \\
\hline
\end{tabular}




\section{Impact on Food Crops}

Table 10 stated that farmers have already replaced seasonal food crops like rice, wheat, potato, pulses, vegetable, and maize for tobacco cultivation that harms the national economy. According to survey results, $25.49 \%$ of respondents replaced seasonal rice and wheat from fields due to tobacco and ranked as one. The following rankings are potato, pulses, vegetables, and Maize.

Kutub and Falgunee (2015) in their case study of Doulotpur, Kushtia found that tobacco cultivation is destroying traditional food cultivation responded by $54 \%$ of the respondents. Mollah (2010) in his study also expressed that the cultivation area and production of food crops started declining in the study area. $\mathrm{He}$ also added that the crop diversity reduced due to tobacco cultivation and only rice and some vegetables are grown in kharif season.

\section{Contributory Factors behind Tobacco Cultivation}

Tobacco cultivation declines soil fertility. It has the involvement of the family members in the cultivation and it also causes some public health hazards. Despite these negative effects, farmers are getting interested in tobacco cultivation mostly due to the availability of a fixed market, high benefit from tobacco cultivation, organizational support from tobacco companies, and their satisfaction with the price provided by the tobacco companies (Table 11).
From survey outputs, availability of fixed market along with high cash benefit provided by tobacco marketing companies promotes the tobacco farming in the study area, and more than $97 \%$ of respondents went assertive with these points. Organizational support from tobacco marketing companies as well as satisfactory selling price from tobacco marketing companies also played a potential role in excelling in tobacco farming in the area. Zohir (2001) in his study reported that farmers are getting interested in tobacco cultivation for its lucrative profitability compared to other crops that completely supports the study. Islam et al. (2010) in their study found that lack of alternative means of livelihood was another reason behind tobacco cultivation on the fertile banks of some rivers like Matamuhuri, Sangu, and Karnafuli.

\section{Factors behind Leaving Tobacco Cultivation}

Survey results from Mithapukur upazila of Rangpur district revealed some hidden factors behind leaving tobacco cultivation (Table 12). Survey results confirmed that $44 \%$ of respondents gave up tobacco cultivation due to health problems caused by tobacco processing and curing. More than one quarter (26\%) of farmers faced an economic problem like lower prices given by the tobacco company and unavailable market for non-registered farmers. Less than one fifth (18\%) farmers left tobacco due to unsatisfactory dealing of the tobacco company for unusual lower grading of the tobacco leaf and giving a lower price.

Table 10: Impact of Tobacco Cultivation on Food Security

\begin{tabular}{|c|c|c|c|c|c|}
\hline \multirow{2}{*}{ Sl. No. } & \multirow{2}{*}{\multicolumn{3}{|c|}{ Farmer's Response }} & \multicolumn{2}{|c|}{ Response (\%) } \\
\hline & & & & Yes & No \\
\hline \multirow{8}{*}{1.} & \multicolumn{3}{|c|}{ Tobacco Cultivation is Replacing other Food Crops } & 54.05 & 45.95 \\
\hline & \multirow{7}{*}{$\begin{array}{l}\text { Crops that are being } \\
\text { Replaced by Tobacco }\end{array}$} & Crops & Response (\%) & \multicolumn{2}{|c|}{ Ranking } \\
\hline & & Rice & 25.49 & \multicolumn{2}{|c|}{1} \\
\hline & & Wheat & 25.49 & \multicolumn{2}{|c|}{1} \\
\hline & & Potato & 21.57 & \multicolumn{2}{|c|}{2} \\
\hline & & Pulses & 13.73 & \multicolumn{2}{|c|}{3} \\
\hline & & Vegetable & 11.76 & \multicolumn{2}{|c|}{4} \\
\hline & & Maize & 1.96 & \multicolumn{2}{|c|}{5} \\
\hline
\end{tabular}

Table 11: Contributory Factors of Tobacco Cultivation

\begin{tabular}{|c|l|c|c|c|}
\hline \multirow{2}{*}{ S1. No. } & \multirow{2}{*}{ Factors } & \multicolumn{3}{|c|}{$\%$ of the Respondents } \\
\cline { 3 - 4 } & Availability of fixed Market for selling tobacco provided by & 97.30 & 2.70 & 1 \\
\hline 1. & $\begin{array}{l}\text { Yes } \\
\text { tobacco marketing companies }\end{array}$ & 97.14 & 2.86 & 2 \\
\hline 2. & High cash benefit proposed by tobacco marketing companies & 89.19 & 10.81 & 3 \\
\hline 3. & Organizational support from tobacco marketing companies & 80.56 & 19.44 & 4 \\
\hline 4. & Satisfactory selling price is given by tobacco marketing companies & \\
\hline
\end{tabular}


Table 12: Factors behind Leaving Tobacco Cultivation

\begin{tabular}{|c|l|c|c|}
\hline SL No. & Factors & Percent (\%) & Rank \\
\hline 1 & Health problem & 44 & 1 \\
\hline 2 & Economic problem & 26 & 2 \\
\hline 3 & $\begin{array}{l}\text { Collision with tobacco } \\
\text { company }\end{array}$ & 18 & 3 \\
\hline 4 & Agricultural problem & 8 & 4 \\
\hline 5 & Social problem & 4 & 5 \\
\hline
\end{tabular}

Park et al. (2018) found in their study that the actual profit of tobacco is not so attractive because farmers do not count their free labor cost as well as the free labor of their family members. Chowdhury (2001) reported in his study that most of the tobacco farmers are deprived of the profit from tobacco by denying a fair price of their products through unscrupulous activities of the middlemen, money lenders, and hostile BAT officials. It is reported that tobacco has only one market provided by the tobacco companies and their agents usually fix the price based on the grade of the tobacco leaves. In this case, farmers faced a loss for not knowing much about the grade of tobacco leaves. Ali et al. (2015) reported that farmers are compromising the negative impact of tobacco cultivation because of economic factors. All these statements strongly support the findings.

\section{Benefit-Cost Ratio}

The Survey result found that the total production cost of tobacco cultivation was $160,000 \mathrm{Tk}$ (BDT) per acre when farmers usually sell their products of 1 acre for 200,000 Tk (BDT). So, the benefit-cost ratio was 1.25. Hassan et al. (2015) found a similar result that the benefit-cost ratio of his study was 1.29.

\section{CONCLUSION}

Tobacco cultivation has serious environmental consequences. This study focused on the impact of tobacco cultivation on environmental degradation, more specifically on soil, air, social-environment, economic status of farmers, public health, and food security. By analyzing the above factors, the contributory factors of tobacco cultivation and the factors behind leaving tobacco cultivation were also identified. Research findings revealed that soil productivity is decreasing in the tobacco field of $62.16 \%$ of tobacco farmers and $70.27 \%$ of tobacco farmers are using more chemical fertilizer per year than the previous year. More than half $(54.05 \%)$ of respondents reported that tobacco is replacing commonly cultivated food crops. Moreover, $51.30 \%$ of tobacco farmers are facing some health hazards due to tobacco cultivation. The present study revealed that $97.14 \%$ of farmers are getting a high benefit, $89.19 \%$ getting organizational support and $80.56 \%$ of farmers are satisfied with the price given by the tobacco company which is the main contributory factors for tobacco cultivation in the study area whereas farmers gave up tobacco cultivation in Mithapukur upazila due to health hazards and unnecessarily underestimating the grade of tobacco leaf. The benefit-cost ratio was found at 1.25. So, it can be said that tobacco cultivation made the cultivated area environmentally vulnerable and unhealthy for living and it also hampers the social environment. It is high time to take necessary steps on preventing environmental degradation caused by tobacco farming. Farmers will leave tobacco cultivation if the government can take initiative measures to ensure alternatives profitable food-producing crop cultivation as tobacco farming.

Acknowledgement: The authors are thankful to Khulna University Research Cell for financial supports and to Soil, Water and Environment Discipline for laboratory facility. The authors are also thankful to all stakeholders in the experimental area.

\section{REFERENCES}

Ali, M.Y., Islam, M.F., Rahman, M. R., Sheema, M.K. and Akhtar, M.R. (2015). Tobacco Farming in Bangladesh and Its Impact on Environment. IOSR Journal of Environmental Science, Toxicology and Food Technology, 9(12): 27-33.

Arcury, T.A., Quandt, S.A., Preisser, J., Bernert, J., Norton, D. and Wang, J. (2003a). High Levels of Transdermal Nicotine Exposure Produce Green Tobacco Sickness in Latino Farmworkers. Nicotine \& Tobacco Research, 5: 315-321.

Arcury, T.A., Quandt, S.A. and Simmons, S. (2003b). Farmer Health Beliefs about an Occupational Illness That Affects Farmworkers: The Case of Green Tobacco Sickness. Journal of Agricultural Safety and Health, 9: 33-45.

Chowdhury, M.A.M. (2001). A Socioeconomic Analysis of Tobacco Cultivation in Bangladesh: A Case Study of Meherpur, Rangpur and Rangunia. Journal of Business Studies, 1: 48-65.

Department of Agriculture Extension (DAE) (2020). Yearly Reports on Tobacco Cultivation Status 2018-19. Department of Agriculture Extension, Ministry of Agriculture, Dhaka, Bangladesh. 
Geist, H.J., 1999. Global Assessment of Deforestation Related to Tobacco Farming. Tobacco Control, 8:18-28.

Hassan, M. M.,Parvin, M.M. and Resmi, S.I. (2015). Farmer's Profitability of Tobacco Cultivation at Rangpur District in the Socio-Economic Context of Bangladesh: An Empirical Analysis. International Journal of Economics, Finance and Management Sciences,3(2): 91-98. https://doi.org/10.11648/ j.ijefm.20150302.13.

Hossain, M.M. and Rahman, M.M. (2013). A Socioeconomic Analysis on Tobacco Cultivation in Kushtia District of Bangladesh. Social Sciences, 2(3):128-134.https://doi.org/ 10.11648/j.ss.20130203.14.

Hu, T-W. and Lee, A.H. (2016). Women in Tobacco Farming: Health, Equality, and Empowerment: A Study Conducted In China, Tanzania And Kenya. Bill and Melinda Gates Foundation. Online document, Retrieved on September 10, 2020. Web (URL) address: https://www.phi.org/uploads/ application/files/cp6dgyk4gsyx1jn3uvzfftd61ohb6sagj 5i9x1sw1y8c7vzm39.pdf

Islam, M. S., Tapan, M.Z. and Nayan, T.B. (2010). Fact Sheet: Tobacco Farming Impact from Peoples' Perspective. Unnayan Dhara, Bangladesh.

Kutub, M.J.R. and Falgunee, N. (2015). Environmental Degradation Due to Tobacco Cultivation in Bangladesh: A Case Study of Doulathpur, Kushtia.Malaysian Journal of Society and Space, 11(7): 1-8.

Lecours, N., Almeida, G. E. G., Abdallah, J.M. and Novotny, T.E. (2012). Environmental Health Impacts of Tobacco Farming: A Review of the Literature. Tobacco Control,21(2): 191-196. http://dx.doi.org/10.1136/tobaccocontrol-2011050318 PMID: 22345244.

Mollah, M.M.U. (2010). Comparative Economics of Producing Alternative Combinations of Rabi Crops by Substituting Tobacco in Bangladesh, Consultant, UBINIG.
Moula, M.S., Hossain, M. S., Farazi, M.M., Ali, M.H. and Mamun, M.A.A. (2018). Effects of Consecutive Two Years Tobacco Cultivation on Soil Fertility Status at Bheramara Upazila in Kushtia District. Journal of Rice Research, 6:1.

Novotny, T.E. and Zhao, F. (1999). Consumption and Production Waste: Another Externality of Tobacco Use. Tobacco Control,8(1):75-80. http://dx.doi.org/10.1136/tc.8.1.75PMID: 10465821.

Park, S.J., Lim, H.S., Lee, K., and Yoo, S.J. (2018). Green Tobacco Sickness among Tobacco Harvesters in a Korean Village. Safety and Health at Work, 9(1):71-74.

Rimmer, L. (2004). BAT's Big Wheeze: The Alternative Report. Online document, Retrieved on August 29, 2020. Web (URL) address: https://ash.org.uk/information-and-resources/tobaccoindustry-information-and-resources/bats-big-wheezethe-alternative-report/

World Health Organization (WHO) (2008). Report on the Global Tobacco Epidemic, the MPOWER Package, Geneva. ISBN: 978-92- 4- 159628- 2. https://www.who.int/tobacco/ mpower/2008/en/

World Health Organization (WHO) (2017). Tobacco and Its Environmental Impact: An Overview. ISBN 978-92-4151249-7.https://www.who.int/tobacco/publications/ environmental-impact-overview/en/

World Health Organization (WHO) (2017). WHO Report on the Global Tobacco Epidemic, 2017: Monitoring Tobacco Use and Prevention Policies. ISBN 978-92-4151282-4.https://www.who.int/tobacco/global_report /2017/en/

Yanda, P.Z. (2010). Impact of Small Scale Tobacco Growing on the Spatial and Temporal Distribution of Miombo Woodlands in Western Tanzania. Journal of Ecology and The Natural Environment, 2: 10-16.

Zohir, S. (2001). Impact of Reforms in Agricultural Input Markets on Crop Sector Profitability in Bangladesh, Bangladesh Institute of Development Studies, Dhaka, Bangladesh. 